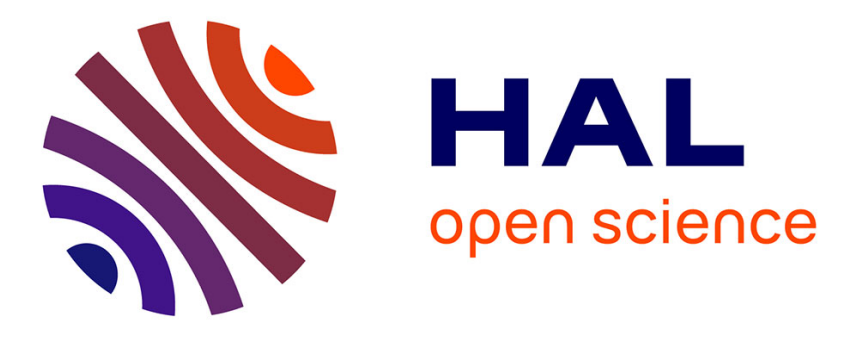

\title{
Recovering illegible writings in fire-damaged medieval manuscripts through data treatment of UV-fluorescence photography
}

Fabien Pottier, Anne Michelin, Laurianne Robinet

\section{- To cite this version:}

Fabien Pottier, Anne Michelin, Laurianne Robinet. Recovering illegible writings in fire-damaged medieval manuscripts through data treatment of UV-fluorescence photography. Journal of Cultural Heritage, 2019, 36, pp.183-190. 10.1016/j.culher.2018.08.012 . hal-03027994

\author{
HAL Id: hal-03027994 \\ https://hal.science/hal-03027994
}

Submitted on 22 Oct 2021

HAL is a multi-disciplinary open access archive for the deposit and dissemination of scientific research documents, whether they are published or not. The documents may come from teaching and research institutions in France or abroad, or from public or private research centers.
L'archive ouverte pluridisciplinaire HAL, est destinée au dépôt et à la diffusion de documents scientifiques de niveau recherche, publiés ou non, émanant des établissements d'enseignement et de recherche français ou étrangers, des laboratoires publics ou privés.

\section{(ㄷ)(1) $\$$}

Distributed under a Creative Commons Attribution - NonCommerciall 4.0 International 


\section{Recovering illegible writings in fire-damaged medieval manuscripts through data treatment of UV-fluorescence photography}

Fabien Pottier ${ }^{1}$, Anne Michelin ${ }^{1}$, Laurianne Robinet ${ }^{1}$

${ }^{1}$ Centre de Recherche sur la Conservation (CRC), MNHN, Sorbonne Université CNRS, MCC, USR 3224, CP21, 36 rue Geoffroy Saint Hilaire, 75005 Paris, France.

\section{ABSTRACT}

When faced with legibility issues on a historical document, several approaches can be explored to recover the degraded contents, such as hyperspectral imaging, XRF scanning or X-ray tomography. Unfortunately due to the time, costs and technical skills required, these imaging techniques cannot be applied to the numerous faded/altered documents present in library collections. Hence, there is a need for a simple imaging procedure that could be applied on a large scale, in the same way libraries and archives are being digitized. The great sensitivity of modern digital camera sensors used for digitization campaigns added to the development of simple image post-treatment tools offer new potentialities regarding this issue. This paper presents a fast and low cost methodology to archive current aspect and reveal hidden contents of documents: UV fluorescence photography used in combination with contrast enhancement treatments (principal component analysis, color space conversion and decorrelation stretch). The efficiency of this approach is demonstrated on the fire-damaged medieval manuscripts collection from Chartres in France.

\section{INTRODUCTION}

As time passes, historical documents are exposed to multiple potential sources of alteration (natural ageing, conservation issues, natural disasters, vandalism, reutilization,...) that can have a strong impact on the legibility of their original content. Recovering access to these invaluable accounts of the past is an important aspect of current research in cultural heritage. The use of stateof-the-art technologies offer new access to thought-to-be irremediably lost writings. Spectral reflection imaging (also referred to as multi- or hyperspectral imaging) [1-3], X-ray tomography [4-7] or XRF mapping $[3,8,9]$ can provide a contrast between the writings and their support based on the imaging of chemical or physical properties (Visible to NIR reflection, X-ray absorption and X-ray fluorescence, respectively). Despite the great technological performances added to meaningful historical (re-)discoveries, these imaging techniques require substantial acquisition and processing time, high technical skills and expensive instrumentation. As a result, they are generally applied to a limited number of rare and/or precious documents, amongst the large number of historical records that could benefit from such recovery tool in library and archive collections.

Hence, there is a need for a fast, low-cost and simple methodology that could be applied on a large scale, in the same way libraries and archival documents are currently being digitized [10]. The primary objective of digitization is to give access to rare, fragile or endangered historical documents, via the accurate recording of the documents appearance, in particular colors. Unfortunately, if altered, the document being recorded as such, will not be exploitable for philology and art history studies.

(C) 2018 published by Elsevier. This manuscript is made available under the CC BY NC user license https://creativecommons.org/licenses/by-nc/4.0/ 
The prestigious medieval manuscripts collection of the Chartres library in France is a good illustration of this situation [11]. Chartres was well known for its famous cathedral school, among the most important occidental intellectual center during the $11^{\text {th }}$ and $12^{\text {th }}$ centuries. On the $26^{\text {th }}$ of May 1944, during an allied bombing of the city, a fire irremediably destroys almost half of the collection. Of the 518 original medieval manuscripts, at least 215 survived the fire but remained in very variable states, from almost intact to entirely calcined. The cumulated actions of fire, water (to extinguish the fire) and the subsequent biological infestation (worms) resulted in different types and levels of alteration. During restoration campaigns, the distorted and agglomerated parchment leaves were separated and flattened. Considering the fragility of the fragments, a digitization campaign was started in 2006 by the Image department of the Institut de Recherche et Histoire des Textes (IRHTCNRS) so the documents could be available again for research [12]. However, in some manuscripts the alteration caused the writings to become partly or totally unreadable (Figure 1), preventing their study. For that reason, historians working on these documents raised the need for a simple imaging solution that would improve the readability of the manuscripts and could be implemented in the digitization process.

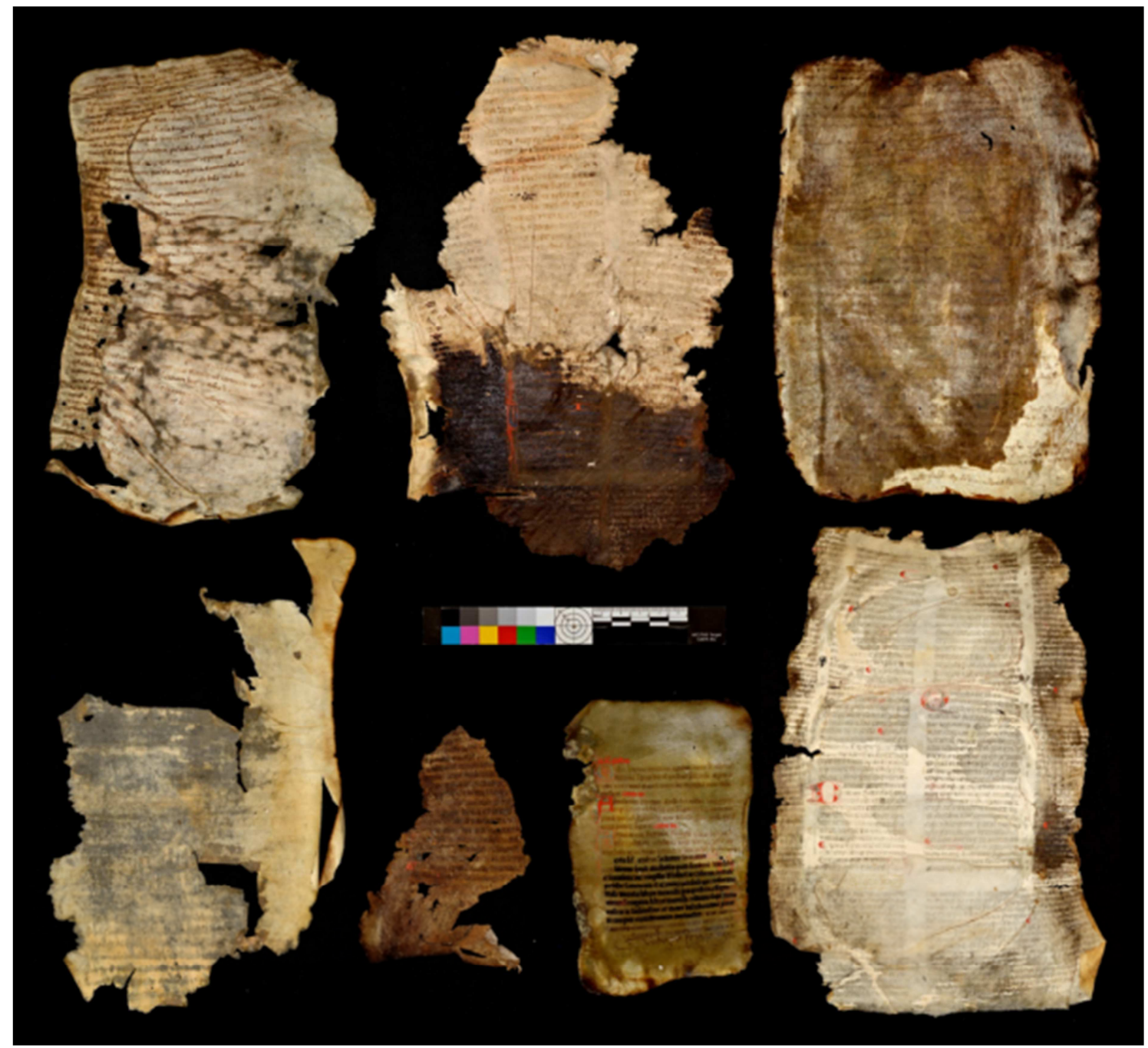

Figure 1. Examples of degraded manuscript fragments from Chartres; from left to right, fragments identification numbers L306-3, L76-2, L28-13 (top), L326-3, MS1032-2, MS1027-68 and L182-1 (bottom). 


\section{RESEARCH AIM}

The great sensitivity of modern camera sensors added to the development of simple image post-treatments open a new range of possibilities to recover degraded writings. In standard digital photographs, color contrast results from the diverging reflection properties of the surface of the document in the visible spectral range. When using UV radiation as a light source on the other hand, the camera sensor does not detect the UV reflected light but instead the visible light resulting from the fluorescence emitted by the parchment. UV-fluorescence photography has been used over a century for the examination of historical documents or works of art to reveal additional information, and the fluorescence colors have sometimes provided clues regarding the chemical nature of the emitting materials [13-16]. However, although accurate color restitution is a key aspect to digital archiving, it is only one way of visualizing photographic data, and other contrast information can be revealed with specific post-treatment tools. As for multispectral images data treatments, color photographs datasets can be explored to enhance contrast and reveal unexpected contents $[1,17,18]$.

In the present paper, a simple methodology using two complementary sources of contrast enhancement was implemented to recover the writings in most of the Chartres manuscript fragments examined. The different approaches developed are illustrated based on examples displaying different alteration types and level of complexity.

\section{EXPERIMENTAL}

Photographs were taken with a Nikon D800 digital camera equipped with a Nikon $60 \mathrm{~mm}$ f/2.8G ED AF-S Micro Nikkor lens, mounted on a copy stand. Two RB-200 flash lights were used to record the reflection properties of the parchments (standard photography), while a Vilber Lourmat UV-A VL-215L lamp (365 nm) was used to record their UV fluorescence. Because the intensity of the fluorescence emission is weak, all photographs were shot in a dark room, on a black fabric, paying attention to get rid of any stray light (daylight, computer screen, LED indicators) or any fluorescent materials (e.g. optical brighteners emitting a strong blue light in modern papers). The aperture was set at $f / 11$. Since all parchments present different emission properties, the exposure time was automatically adjusted according to the fluorescence intensities (generally several seconds). The data were recorded as raw files (.neff) in order to avoid any data compression (and loss of useful information) before image treatment. Photographs were color-calibrated with the AIC-PhD target (see the center of Figure 1). Open-source software ImageJ was used for all the data treatments, updated with different plugins: Color Inspector 3D (3D visualization of the chromatic distribution in a color space of interest), MSA_514 (Principal Component Analysis (PCA) of a color image), Color Transformer ( $\mathrm{L}^{*} \mathrm{a}^{*} \mathrm{~b}^{*}$ to HSL color space conversion) and DStretch (decorrelation stretch contrast enhancement).

A corpus of manuscript fragments was selected in order to cover the diversity of alteration encountered in the collection. Four main types of alterations were identified, sometimes present simultaneously on certain fragments: darkened (calcined) substrate, transparent (gelatinized) substrate, faded (washed-out) writings and superimposition of matter on the writings. In total, 132 manuscripts fragments were photographed (back and front) under standard (visible) and UV-A illumination. Representative examples are shown and discussed in the results. 


\section{RESULTS AND DISCUSSION}

The efficiency of UV fluorescence photography was rapidly evidenced for a large number of Chartres manuscript fragments. In the example shown in Figure 2 (top), the action of fire considerably darkened the parchment substrate, preventing any clear reading of the contents under normal lighting conditions. Additionally, the writing from the front and the back of the fragment are both seen in the photographs (see the word written in red), due to transparency of the substrate. The two problems are solved simultaneously by the UV-fluorescence (bottom of Figure 2). Ultraviolet radiations provide a better contrast between the ink and the substrate and the weak penetration of the radiation allows a clear separation of the writing between the two sides of the page.

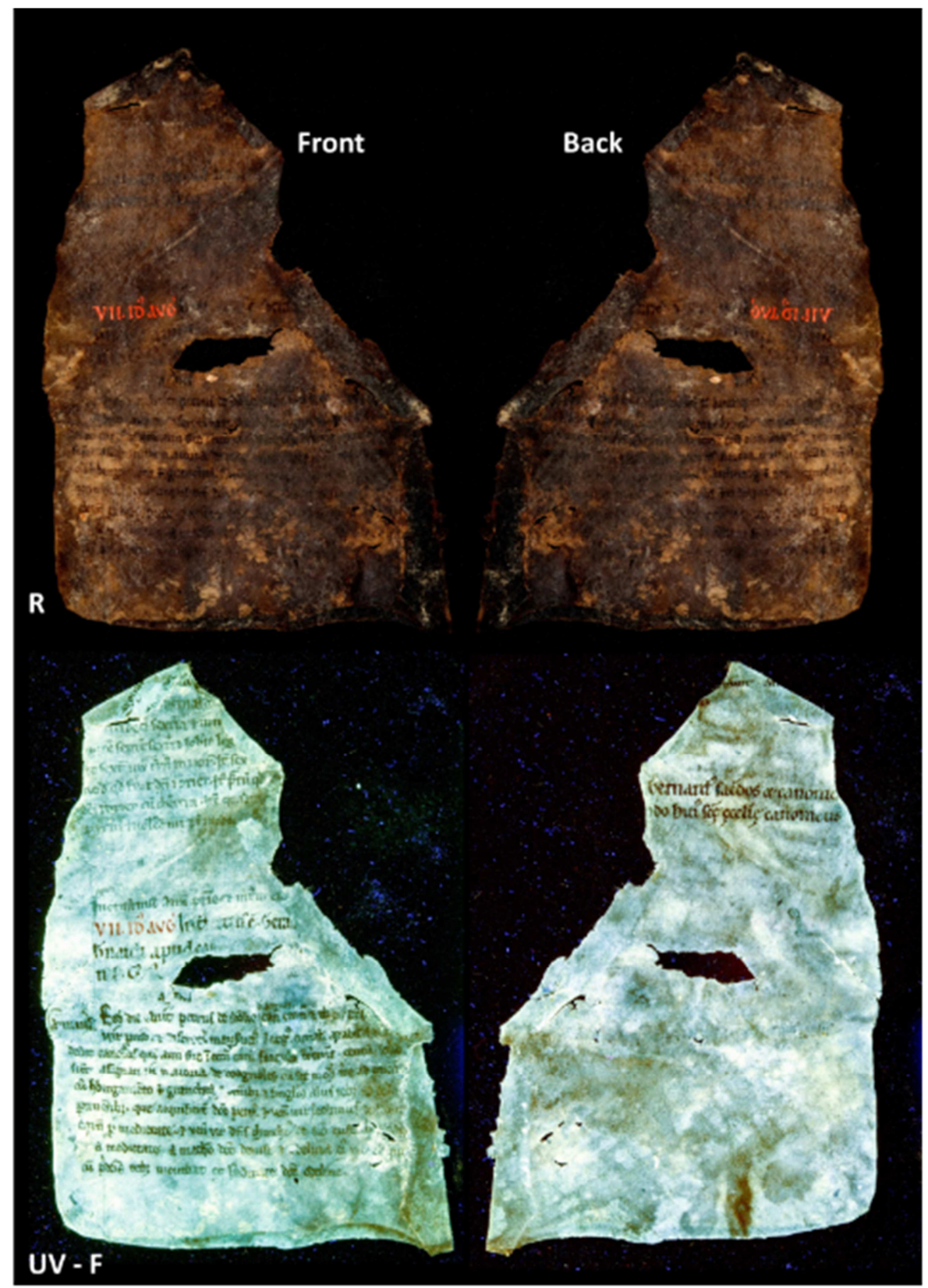

Figure 2. Visible reflection and UV fluorescence photographs of the two sides of fragment MS1032-1 
This simple and direct approach to recover the text works well when the parchment support is altered (calcined and/or transparent), however it is not sufficient when the writings have been washed-out. In fragment L326-1, for example (Figure 3, R), the ink was erased to such an extent that it is difficult to know if a text was originally present. The UV-fluorescence photograph reveals lines of text, but contrast is so subtle that reading remains impossible (Figure 3, UV-F). In this type of alteration, several digital enhancement techniques can be applied to increase the reading contrast of the photograph.

The images shown in Figure 1 to Figure 3 were color calibrated so that the fragments appear as a human eye would perceive them when looking at them under visible or UV light. However, more information can be extracted from these images if this color rendering is abandoned. The color described in each pixel of a digital image is coded with the three color channels Red, Green and Blue (RGB), mixed in different proportions to create all visible colors. Hence, a color photograph can be considered as a stack of three photographs (left of Figure 4). Temporarily putting aside the spatial repartition of the colors in a photograph, one can study the distribution of its chromatic cloud (total hue variation) in a three dimensional space, where each RGB channel is associated with a dimension (right of Figure 4). Each color present in the photograph is plotted in this volume, and the chromatic variations are displayed as clouds with progressive tones of colors rather than discrete color values.

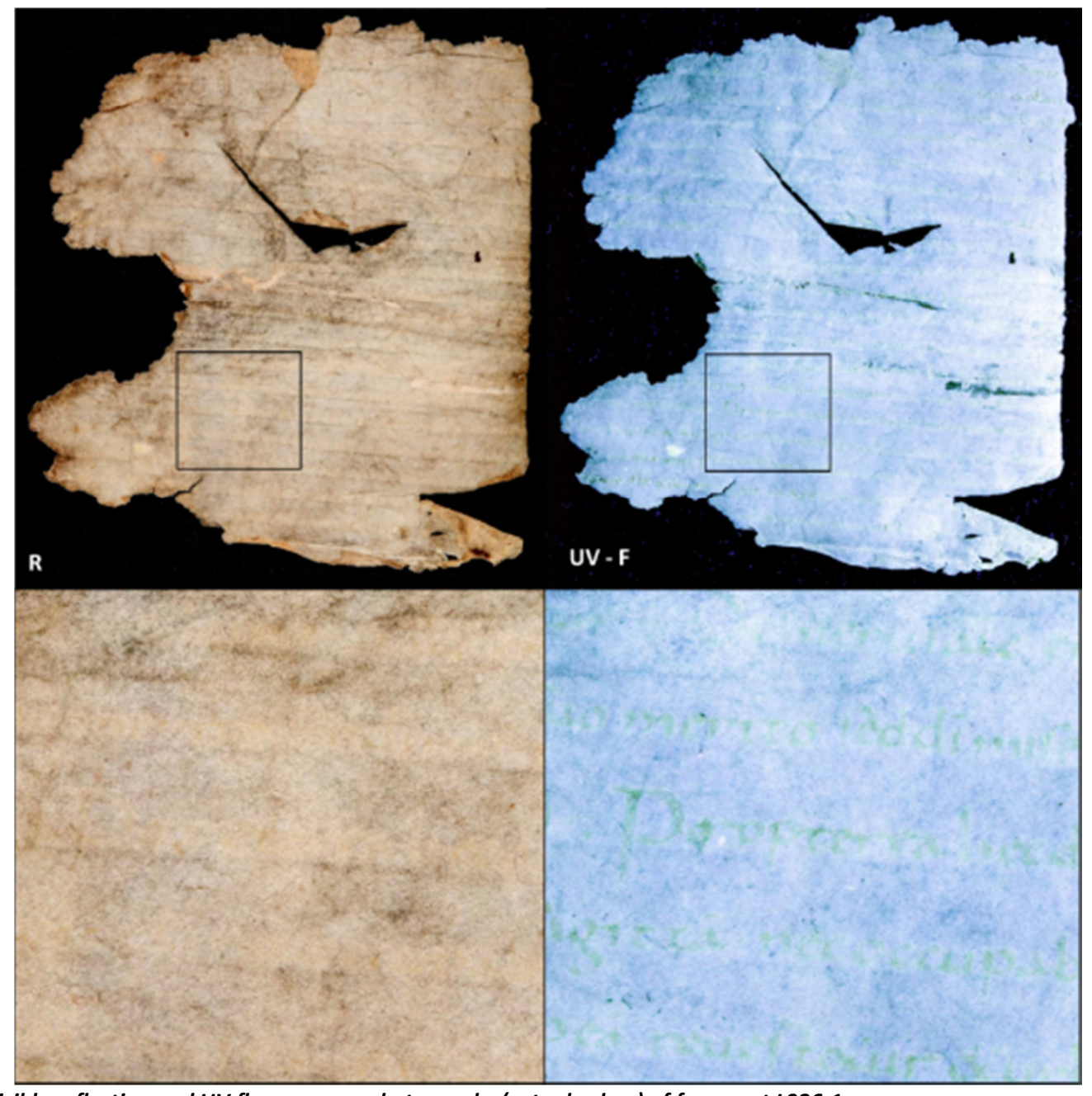

Figure 3. Visible reflection and UV fluorescence photographs (actual colors) of fragment L326-1 


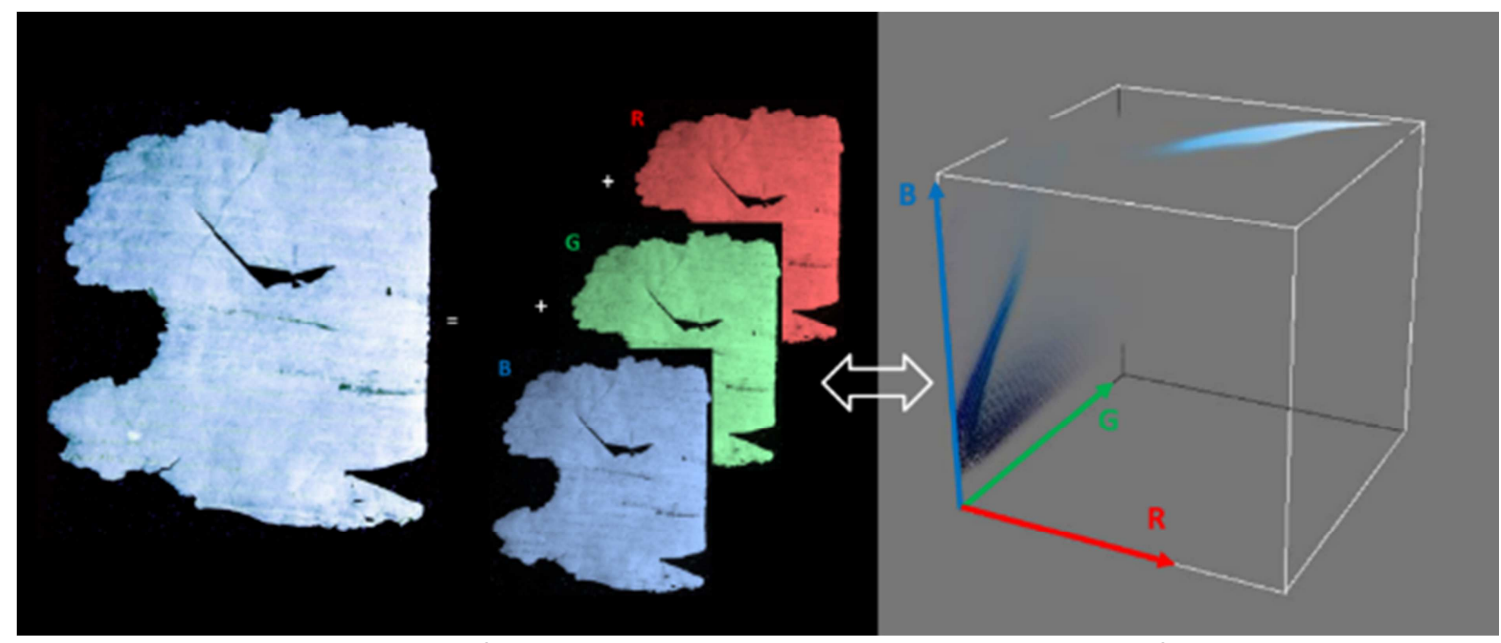

Figure 4. Schematic representation of a digital photograph content as a superimposition of $R, G$ and $B$ color channels (left), and color distribution in the RGB chromatic space (Color Inspector 3D plugin)(right)

In order to solve the lack of writing legibility in a manuscript, the study of the photograph chromatic dispersion in the RGB space helps to visualize which color dimension is the most relevant to maximize the text contrast. For the UV-fluorescence photograph of fragment L326-1, three clouds are observed in the RGB chromatic space (right of Figure 4), corresponding to the dark colors of the background, and the light blues and dark blues of the fluorescence. The blue (B) channel is the dimension along which the colors associated with the text are the most contrasted, i.e. the axis along which there is the largest text/substrate value gap. Therefore, it is relevant to visualize this channel by itself and ignore the two others. A grey level representation of the B values of the fragment is then obtained. After contrast optimization, by adjusting the maximum and minimum values of the histogram, writings are revealed (Figure 5).

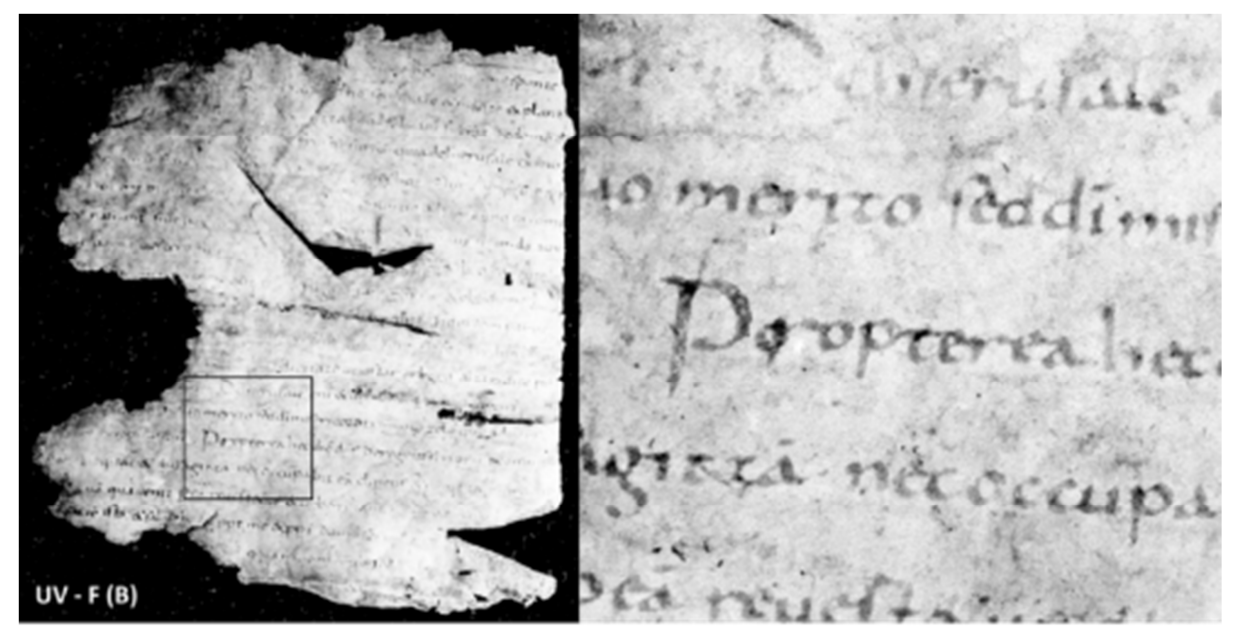

Figure 5. Blue channel (B) after contrast optimization of the UV fluorescence photograph of fragment L326-1

Although great improvement was obtained, this result can still be perfected since the text in the entire fragment is not yet readable. In order to ensure that all the potential contrast information contained in the photograph has been explored, a statistical analysis (Principal Component Analysis (PCA)) can be applied. This data treatment relies on the study of the 3D distribution of the chromatic cloud and calculates three composite dimensions (orthogonal to each other). Each new dimension is 
composed of a combination of the former R, G and B dimensions (in different proportions) and represents the color information in a re-organized fashion. The aim of this manipulation is to project the chromatic data along new axes that offer different contrast modes (Figure 6). Three new images of the fragment (one for each component) are obtained providing three new views of the document. In fragment L326-1, the third principal component concentrates the text/substrate contrast information giving the best reading conditions (Figure 7).

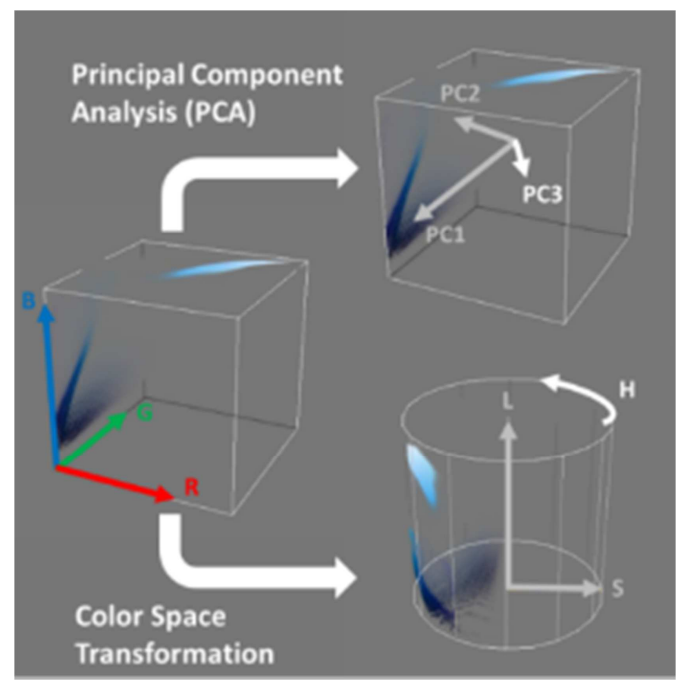

Figure 6. Color data manipulations involved in photograph contrast maximization

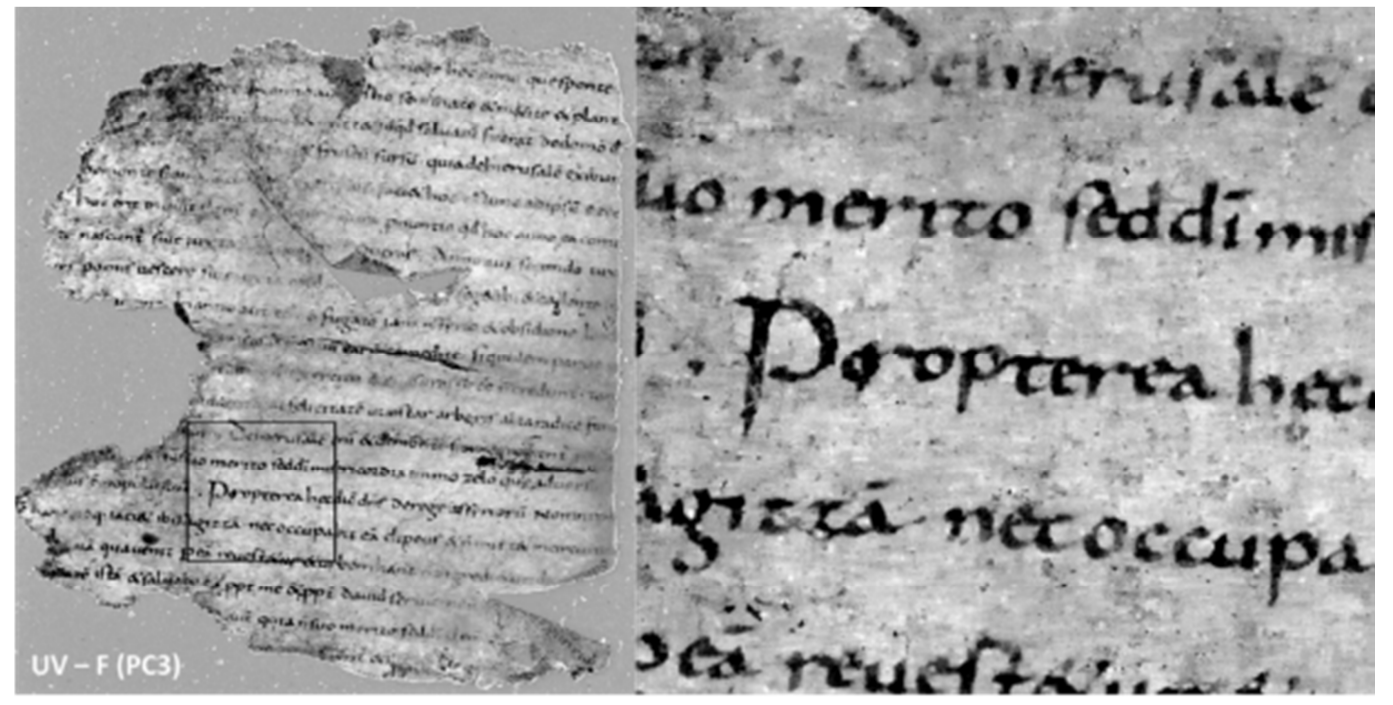

Figure 7. Third principal component (PC3) of the UV fluorescence photograph of fragment L326-1

Principal Component Analysis is a very powerful tool to explore the contrast potentialities hidden in a color digital photograph, and ensures that all relevant information contained in an image has been considered [1]. Calculations take few seconds per image (of $36 \mathrm{MPx}$ ) to evaluate and apply the RGB to PC1,PC2,PC3 transformation matrix. This calculation must be performed for each photograph (or detail of interest) since the PC1,PC2,PC3 system is specific for each chromatic distribution. Although this calculation time appears negligible, it may become substantial if the treatment has to be applied to a large number of photographs (as for the thousands of fragments from Chartres). 
An alternative to get a similar rendering with a shorter calculation time (avoiding statistical analysis) is to convert the data to a different standard color space. In this operation the conversion matrix is always the same and therefore independent of the image content. Good results are obtained using the HSL color space relying on three different contrast modes Hue, Saturation, Lightness (see the right bottom of Figure 6), and the best reading conditions are obtained by mapping the hue $(\mathrm{H})$ values in grey levels. As another demonstration, the methodology was applied to fragment L306-1, where almost no text appeared visible in the realistic color renderings (top of Figure 8). The third principal component from the PCA treatment of the UV photograph reveals lines of writings, and a similar contrast is obtained with the (faster) conversion to the HSL $(\mathrm{H})$ color space. This similarity in the results of the two treatments was observed for all fragments studied.

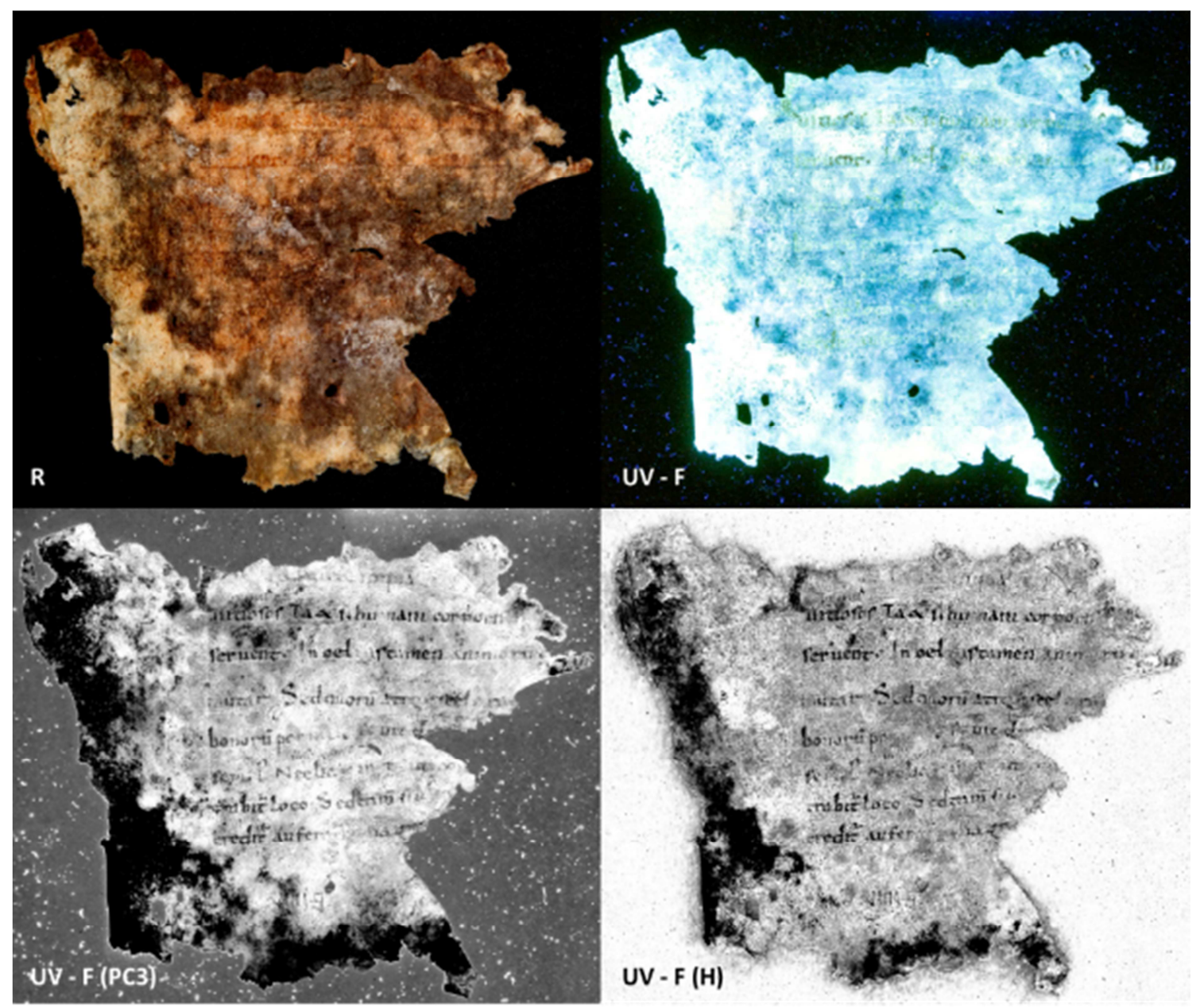

Figure 8. Visible reflection and UV fluorescence photographs (actual colors, PC3 and H values) of fragment L306-1

This observation helps understand the exact origin of the text/support contrast, not explicitly given by the PCA. The contrast in hue $(\mathrm{H})$ implies that the area where the writings used to be generate a fluorescence with a slightly different shade than the fluorescence emitted by the unwritten parchment substrate. These different emission properties may indicate a structural modification or the presence of different fluorophores. Lightness (L), on the other hand does not provide any contrast (image not shown), because text and parchment emit at exactly the same intensity level. The human brain cannot perceive low hue contrast, this is the reason why the text is so hard to read in the color photograph. 
Despite the improvement offered by these contrast treatments, in some cases the image quality does not allow a proper reading of the text. In the example Figure 9, the large size of the fragment L451-1 necessitated to enlarge the field of view, which considerably lowered the spatial resolution of the images. Small details (specifically the writings of interest) are consequently very hard to discern, even after UV-fluorescence data treatments (see UV-F (PC3) (detail), Figure 9). To overcome this problem, macrophotography should be used to focus on details and improve the image spatial resolution. The image treatment is then applied to the macrophotograph and a much better readability is obtained (compare the results of the PCAs, Figure 9).

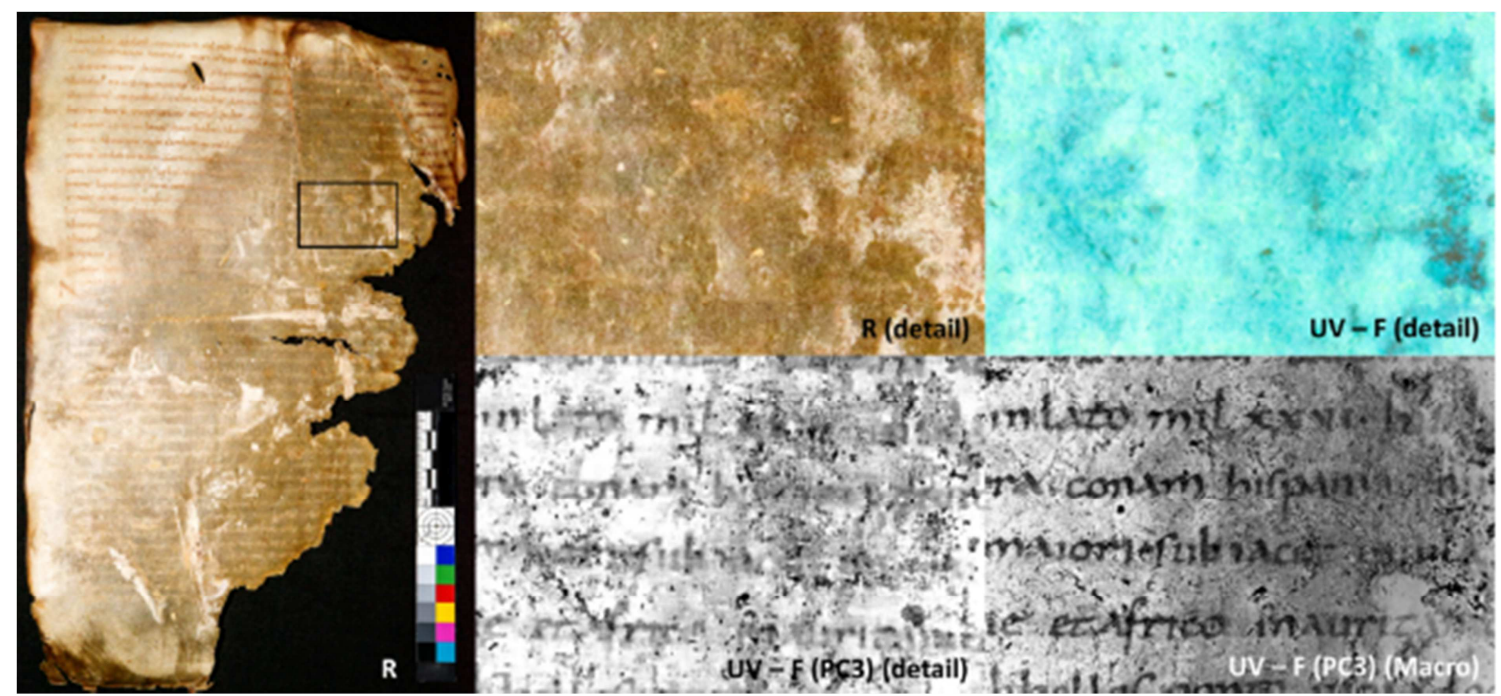

Figure 9. Full scale and macro visible reflection and UV fluorescence photographs (actual colors and Third principal component) of fragment L451-1 (details are extracted from the photographs of the complete fragment)

Another enhancement treatment worth mentioning, is implemented in the very handy DStretch plugin developed by John Harman [17] and based on a decorrelation stretch algorithm $[19,20]$. This plugin was designed for rock art color enhancement of standard (reflection) photographs (see [21-24] for example), but has occasionally been applied to other materials, such as an Egyptian wall painting [25] and a Mesoamerican manuscript [26]. We show that it can be equally useful for the enhancement of medieval writings (or any other graphical contents) in UV fluorescence color photographs (Figure 10). Though the DStretch plugin does not seem to offer better results than the PCA or HSL conversion (compare Figure 10 to Figure 9, Figure 8 and Figure 7), its user-friendly interface greatly facilitates the color data exploration for non-specialists. 


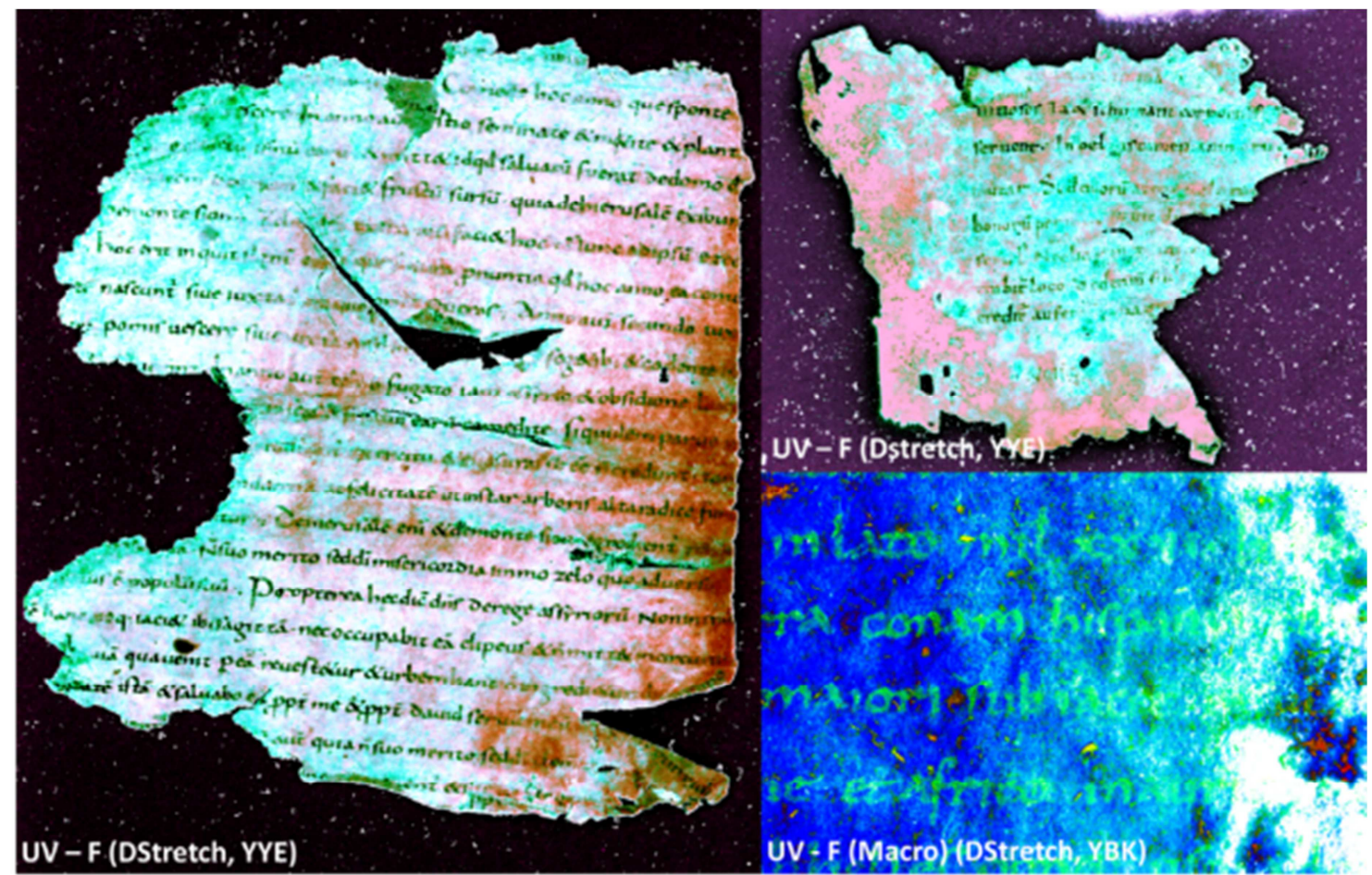

Figure 10. Contrast enhancement of UV fluorescence photographs of fragments L326-1 (left), L306-1 (top right) and L45-1 (bottom right) with the DStretch plugin in ImageJ.

From a practical point of view, the presented methodology only requires a digital camera, a UV-A light source and rely on open source software and plugins for the image treatments, therefore the cost investment is limited. To assess the possibility of using the methodology on a large scale, a test was carried as part of the digitization process with the image team of the IRHT at the library in Chartres. This experiment showed that it only takes half a day and two persons to digitize 64 fragments (back and front), in standard and UV-fluorescence photography (so about 2 minutes per fragment, which roughly doubles the time necessary for a standard digitization). The methodology could probably be further optimized using an automated system to collect photographs with both illuminations with only one person. Lastly, the ease of use of the different contrast enhancement tools was tested, validated by historians, and the deteriorated fragments already revealed relevant new historical data [27-29].

\section{CONCLUSION}

UV fluorescence photography proved to be a powerful tool to (at least partially) reveal initially illegible content in most of the manuscripts fragments from Chartres that were studied. In the cases of darkened and/or transparent substrate, the accurate color restitution of the UV fluorescence was generally sufficient to reveal the text, whilst an extra step of color contrast optimization was necessary when the inks were washed out. Unfortunately, some fragments are in such an advanced degradation state that the presented methodology did not provide much legibility improvement (for example fragment L326-3, at the bottom left of Figure 1). Neither would it help when matter is superimposed on top of the writings (eg. fibers from blotting papers used during the emergency conservation treatments (not shown)). In these cases, it seems that more sophisticated imaging instrumentations, such as X-Ray based techniques, will have to be explored. 
The ever improving capabilities of imaging sensors in modern digital cameras offer new possibilities for the study of historical documents. UV-fluorescence generates useful complementary visualization mode to standard visible reflection photographs. The additional color contrast optimization through PCA, color space conversion or decorrelation stretch helps to reveal hidden contents and ensures that all relevant information contained in a photograph is explored. Not only does digital photography give great results in terms of contrast enhancement, but its implementation is fast, simple, inexpensive and realistically applicable on a large scale for collections. Moreover, none of the acquisition or image treatment steps require specific scientific or technical skills, so this approach can be used by non-specialists.

Regarding future research, one should note that the presented contrast optimization procedure through color space transformation is applicable to any other types of digital color photography (reflection, transmission, IRFC [30],..) of any degraded/faded polychromatic surfaces (rock art, manuscripts, but also drawings, paintings, ceramics, textiles, analog photographs...). Therefore, this methodology could potentially be of interest in these various fields.

\section{AKNOWLEDGEMENT}

The authors wish to thank Catherine Merlin and Michèle Neveu of the Médiathèque I'Apostrophe in Chartres, who permitted access to the collection and greatly facilitated the work. We are also grateful to Claudia Rabel and Dominique Poirel from the Institut de Rercherche et d'Histoire des Textes (IRHT-CNRS) for their expertise as medieval philologists, and to Gilles Kagan from the IRHT-CNRS for sharing his experience in medieval manuscript digitization. This project was funded with a post-doctoral fellowship of the Fondation des Sciences du Patrimoine/LabEx PATRIMA (ANR10-LABX-0094-01).

\section{BIBLIOGRAPHY}

[1] R.L. Easton, W.A. Christens-Barry, K.T. Knox, Spectral image processing and analysis of the Archimedes Palimpsest, Eur. Signal Process. Conf. (2011) 1440-1444.

[2] L. Snijders, T. Zaman, D. Howell, Using hyperspectral imaging to reveal a hidden precolonial Mesoamerican codex, J. Archaeol. Sci. Reports. 9 (2016) 143-149. doi:10.1016/j.jasrep.2016.07.019.

[3] E. Pouyet, S. Devine, T. Grafakos, R. Kieckhefer, J. Salvant, L. Smieska, A. Woll, A. Katsaggelos, O. Cossairt, M. Walton, Revealing the biography of a hidden medieval manuscript using synchrotron and conventional imaging techniques, Anal. Chim. Acta. 982 (2017) 20-30. doi:10.1016/j.aca.2017.06.016.

[4] I. Bukreeva, A. Mittone, A. Bravin, G. Festa, M. Alessandrelli, P. Coan, V. Formoso, R.G. Agostino, M. Giocondo, F. Ciuchi, M. Fratini, L. Massimi, A. Lamarra, C. Andreani, R. Bartolino, G. Gigli, G. Ranocchia, A. Cedola, Virtual unrolling and deciphering of Herculaneum papyri by X-ray phase-contrast tomography, Sci. Rep. 6 (2016) 27227. doi:10.1038/srep27227.

[5] D. Mills, O. Samko, P. Rosin, K. Thomas, T. Wess, G.R. Davis, Apocalypto: revealing the unreadable, SPIE Opt. Eng. + Appl. 8506 (2012) 85060A-5. doi:10.1117/12.928917.

[6] D. Baum, N. Lindow, H.C. Hege, V. Lepper, T. Siopi, F. Kutz, K. Mahlow, H.E. Mahnke, Revealing 
hidden text in rolled and folded papyri, Appl. Phys. A Mater. Sci. Process. 123 (2017) 1-7. doi:10.1007/s00339-017-0808-6.

[7] V. Mocella, E. Brun, C. Ferrero, D. Delattre, Revealing letters in rolled Herculaneum papyri by X-ray phase-contrast imaging, Nat. Commun. 6 (2015) 1-6. doi:10.1038/ncomms6895.

[8] J.R. Duivenvoorden, A. Käyhkö, E. Kwakkel, J. Dik, Hidden library: Visualizing fragments of medieval manuscripts in early-modern bookbindings with mobile macro-XRF scanner, Herit. Sci. 5 (2017) 1-10. doi:10.1186/s40494-017-0117-6.

[9] F. Albertin, A. Astolfo, M. Stampanoni, E. Peccenini, Y. Hwu, F. Kaplan, G. Margaritondo, X-ray spectrometry and imaging for ancient administrative handwritten documents, X-Ray Spectrom. 44 (2015) 93-98. doi:10.1002/xrs.2581.

[10] L. Watteeuw, M. Collier, What do we lose when we lose a library ?, in: Proc. Conf. Held KU Leuven 9-11 Sept. 2015, n.d.

[11] D. Poirel, C. Rabel, P. Stirnemann, Rediscovering the Manuscripts from Chartres, (n.d.). https://www.manuscrits-de-chartres.fr/en (accessed March 21, 2018).

[12] Bibliothèque virtuelle des manuscrits médiévaux, (n.d.). http://bvmm.irht.cnrs.fr/ (accessed March 21, 2018).

[13] C.M. Baldia, K.A. Jakes, Photographic methods to detect colourants in archaeological textiles, J. Archaeol. Sci. 34 (2007) 519-525. doi:10.1016/j.jas.2006.06.010.

[14] I. Montani, E. Sapin, A. Pahud, P. Margot, Enhancement of writings on a damaged medieval manuscript using ultraviolet imaging, J. Cult. Herit. 13 (2012) 226-228. doi:10.1016/j.culher.2011.09.002.

[15] A. Cosentino, Practical notes on ultraviolet technical photography for art examination, Conserv. Património. 21 (2015) 53-62. doi:10.14568/cp2015006.

[16] J.J. Rorimer, Ultra-violet rays and their use in the examination of works of art, The Metropolitan Museum of Art, New-York, 1931.

[17] J. Harman, Using decorrelation stretch to enhance rock art images, Am. Rock Art Res. Assoc. Annu. Meet. May28, 2005. (2005).

[18] W. Boussellaa, H. El Abed, A. Zahour, A Concept for the Separation of Foreground / Background in Arabic Historical Manuscripts using Hybrid Methods, J. Univers. Comput. Sci. 14 (2006) 2006.

[19] A.R. Gillespie, A.B. Kahle, R.E. Walker, Color enhancement of highly correlated images. I. Decorrelation and HSI contrast stretches, Remote Sens. Environ. 20 (1986) 209-235. doi:10.1016/0034-4257(86)90044-1.

[20] R.E. Alley, Algorithm Theoretical Basis Document for Decorrelation Stretch, NASA, JPL. (1996).

[21] J.L. Le Quellec, F. Duquesnoy, C. Defrasne, Digital image enhancement with DStretch : Is complexity always necessary for efficiency?, Digit. Appl. Archaeol. Cult. Herit. 2 (2015) 55-67. doi:10.1016/j.daach.2015.01.003.

[22] D. Caldwell, U. Botzojorns, An historic sign, possible Mesolithic menhir, DStretch, and problems in dating rock art to the Sauveterrian in the Massif de Fontainebleau, J. Archaeol. Sci. 42 (2014) 140-151. doi:10.1016/j.jas.2013.09.023. 
[23] C. Defrasne, Digital image enhancement for recording rupestrian engravings: Applications to an alpine rockshelter, J. Archaeol. Sci. 50 (2014) 31-38. doi:10.1016/j.jas.2014.06.010.

[24] J. Fernández-Lozano, G. Gutiérrez-Alonso, M.Á. Ruiz-Tejada, M. Criado-Valdés, 3D digital documentation and image enhancement integration into schematic rock art analysis and preservation: The Castrocontrigo Neolithic rock art (NW Spain), J. Cult. Herit. 26 (2017) 160166. doi:10.1016/j.culher.2017.01.008.

[25] L. Evans, A. Mourad, DStretch and Egyptian tomb paintings : A case study from Beni Hassan, J. Archaeol. Sci. Reports. 18 (2018) 78-84. doi:10.1016/j.jasrep.2018.01.011.

[26] A. Brownstone, E. Hill Boone, N. Johnson, B. Van Doesburg, The Lienzo of Tlapiltepec: a painted history from the Northern Mixteca, University of Oklahoma Press, Norman, 2015.

[27] J. Fronska, Rescapé du feu et de l'eau. L’histoire partiellement révélée du Volumen parvum chartrain, ms. 273, in: Actes La Journée d'étude Les Rescapés Du Feu L'imagerie Sci. Au Serv. Des Manuscrits Chartres, Editions de la Société Archéologique d'Eure et Loire, Chartres, n.d.

[28] P. Chastang, Lectures d'un obituaire Chartrain du 14ème siècle, in: Actes La Journée d'étude Les Rescapés Du Feu L'imagerie Sci. Au Serv. Des Manuscrits Chartres, Editions de la Société Archéologique d'Eure et Loire, Chartres, n.d.

[29] I. Bretthauer, Les registres capitulaires de Chartres, XIIIe-XIVe siècle : essai de reconstitution, in: Actes La Journée d'étude Les Rescapés Du Feu L'imagerie Sci. Au Serv. Des Manuscrits Chartres, Editions de la Société Archéologique d'Eure et Loire, Chartres, n.d.

[30] A. Cosentino, Infrared Technical Photography for Art, E-Preservation Sci. (2016) 1-6. 